\title{
Alpinia calcarata: potential source for the fabrication of bioactive silver nanoparticles
}

\author{
Pramila Khandel, Sushil Kumar Shahi, Deepak Kumar Soni, Ravi Kumar Yadaw and Leeladhar Kanwar
}

\begin{abstract}
In the present study silver nanoparticles fabricated by using leaf extract of Alpinia calcarata. We have also studied the effect of various experimental parameters viz., metal ion concentration, $\mathrm{pH}$ and incubation period on nanoparticle biosynthesis. Results of optimization showed that metal ion concentration of $1.5 \mathrm{mM}$, alkaline pH and incubation period of $12 \mathrm{~h}$ were the optimum conditions for metal nanoparticle biosynthesis. Synthesized silver nanoparticles were characterized by UV-Visible spectroscopy, Dynamic light scattering (DLS), Zeta potential analysis, Fourier transform infrared spectroscopy (FTIR), Inductively coupled plasma-optical emission spectrometry (ICP-OES), Transmission electron microscopy (TEM) and X-ray diffraction analysis (XRD). The UV-visible spectrum shows a sharp peak at $420 \mathrm{~nm}$ which was due to the surface plasmon resonance of the silver nanoparticles. Effect of several phytochemicals present in A. calcarata, on synthesis of silver nanoparticles was studied by Fourier transform infrared spectroscopy. The results indicate that the flavonoids, phytosterol, quinones and phenolic compounds present in the plant extract plays a major role in formation of silver nanoparticles in their respective ions in solution. Results of TEM and XRD analysis showed that synthesized silver nanoparticles were mostly spherical in shape with an average diameter of $27.2 \pm 0.2 .5 \mathrm{~nm}$ and highly crystalline in nature. Moreover the synthesized silver nanoparticles were also evaluated for their potential antibacterial and antioxidant activities. It showed good antibacterial activity as well as antioxidant activity. Thus the obtained result provides a scientific support that leaf extract of $A$. calcarata can be used efficiently in the production of potential bioactive silver nanoparticles with several pharmaceutical applications.
\end{abstract}

Keywords: Fabrication, Silver nanoparticles, Process optimization, Antibacterial activity, Antioxidant activity

\section{Introduction}

Fabrication methods for the synthesis of metal nanoparticles using green chemistry principle have gained significant attention in the past decades. This is mainly due to there is no requirement of toxic chemicals for synthesis protocol. The chemical synthesis approaches have drawback that during synthesis process the colloidal solution being contaminated by several by-products as a result of chemical reactions. Thus, to overcome all these problems there is a need to develop alternative green process which does not need any harmful chemicals. Considerable works have been put to develop eco-friendly approaches

*Correspondence: sushilkshahi@gmail.com

Department of Botany, Bioresource Tech Laboratory, Guru Ghasidas

Vishwavidyalaya, Bilaspur, Chhattisgarh 495009, India for the synthesis of nanoparticles. Microbes and plants are currently used for the synthesis of nanoparticles. The use of plants for the synthesis of nanoparticle is rapid, low cost, environmental benign and a single step method. Plant extract contains a variety of phytochemicals compounds such as flavonoids, terpenoids, phenols, alkaloids some plant enzymes like hydrogenases, reductases, etc. which act as a reducing and capping agent in the presence of metal salts [1].

Recently metal nanoparticles are gaining the interest of scientist for the novel methods of synthesis because they exhibit unique physicochemical properties including optical catalytic, magnetic, electronic and antimicrobial properties [2]. They have a high surface area and a high fraction of atoms. Nanomaterials such as $\mathrm{Ag}, \mathrm{Au}, \mathrm{Cu}, \mathrm{Zn}$, Pt and Pd have been synthesized by various methods, 
including biological entities using bacteria, fungi, algae and plants [3]. Among them silver (Ag) nanoparticles play a considerable role in field of medical and biological sciences due to its significant physicochemical properties. Ag nanoparticles are reported to exhibit great antibacterial, antifungal, anti-inflammatory, antioxidant and antiviral activities [4]. Nanoparticles play a crucial role in drug delivery, tissue engineering, gene delivery, artificial implants, diagnosis, imaging and sensing [5]. It has been found that a highly reactive metal nanoparticle shows excellent antimicrobial activities against bacteria [6] Silver nanoparticles have wide applications in medicines including skin creams and ointments containing silver to inhibit infection of burns and wounds and medical devices.

In the present investigation, we discuss the synthesis of bioactive Ag nanoparticles using the leaf extract of Alpinia calcarata as the biomaterial. A. calcarata is also known as Snap Ginger, which is a plant native to India, belongs to the Zingiberaceae family, as it is commonly available medicinal plant, used for synthesis of $\mathrm{Ag}$ nanoparticles. A. calcarata is a perennial herb with horizontal root stock and full leafy stem. The leaves of the plant are simple, alternative $25-35 \mathrm{~cm}$ in length and are $2.5-5 \mathrm{~cm}$ broad [7]. It is reported that the compounds isolated from the Zingiberaceae plants were found to have anticancer activity against several cell lines and also have strong anti-inflammatory and antioxidant activities [8]. Rhizome of the plant also contains various secondary metabolites majorly diterpenoids, some of them are reported as cytotoxic and can induce cell cycle arrest such as Calcarathan D, Calcarathan E etc. They also show excellent antibacterial activities against some pathogenic Gram +ve and Gram -ve bacteria. Additionally, A. calcarata is also used for the treatment of various diseases such as warming digestive tonic, carminative, stomachic, stimulant, expectorant and fungal infections. Plant is also used as tonic, aphrodisiac and diuretic, in the treatment of headache, lumbago diabetes, chest pain, rheumatic pains, bronchitis, dyspepsia, sore throat, impotence and diseases of kidney and liver. It is particularly considered for its efficacy in chest complains. A wide variety of chemical compounds and various bioactivities, including antimicrobial and antioxidant properties were reported in phytochemical studies from this plant. Ag nanoparticles have been synthesized using several natural products like Crocus sativus L. [9], Azadirachta indica [10], Alysicarpus monilifer [11], Camellia sinensis [12], Glycine max [13], Cinnamon zeylanian [14], Syzygium aromaticum [15] etc. Plants give a better platform for nanoparticle synthesis as they do not contain any toxic chemicals along with this they also provide natural stabilizing agent. Other advantages may include, use of plant extracts reduces the cost of microorganism's isolation and culture media increases the cost ambitious viability over nanoparticle synthesis through microorganisms [16].

The aim of the present investigation was to synthesize the silver nanoparticles using leaf extract of $A$. calcarata. Phytochemical investigation of leaf extract of plant to evaluate the possible biomolecules responsible for the bioreduction and stabilization of synthesized nanoparticles. Optimization of various reaction conditions for nanoparticle synthesis such as the metal ion concentration, $\mathrm{pH}$ and incubation period. Furthermore characterization of synthesized silver nanoparticles by UV-Vis spectroscopy, FTIR, DLS, zeta potential measurements, ICP-OES, TEM and XRD analysis and evaluation of their potentiality for antibacterial activity against pathogenic microbial strains and antioxidant activities.

\section{Materials and methods}

\subsection{Sample collection}

Fresh leaves of Alpinia calcarata (Snap Ginger) were collected from campus of Department of Botany, Guru Ghasidas Vishwavidyalaya, Bilaspur, Chhattisgarh, India. Silver nitrate and other analytical grade chemicals were purchased from Hi-media laboratories, Mumbai, India. The bacterial culture of Escherichia coli (MTCC-44), Pseudomonas aeruginosa (MTCC-424) and Staphylococcus aureus (MTCC-96) were obtained from microbial type culture collection (MTCC), Chandigarh, India.

\subsection{Preparation of plant leaf extract}

Aqueous extract of leaf of $A$. calcarata were prepared using freshly collected leaves. They were surface sterilized with running tap water followed by distilled water and finally chopped into fine pieces. About $10 \mathrm{~g}$ of finally incised leaf was boiled with $100 \mathrm{ml}$ of distilled water for $30 \mathrm{~min}$. The extract was allowed to cool than filtered with Whatman No. 1 filter paper. Filtrate was collected and stored at $4{ }^{\circ} \mathrm{C}$ for further experiment.

\subsection{Phytochemical investigation}

Qualitative phytochemical analysis of A. calcarata was performed using the standard protocols described by Jigna and Sumitra [17] for determination of presence of several phytoconstituents like flavonoids, alkaloids, glycosides, tannins, resins, phytosterols, saponins, terpenes, quinones and phenolic compounds. The results of these tests were showed qualitatively as positive $(+)$ or negative $(-)$.

\subsection{Biosynthesis of silver nanoparticles}

For biosynthesis of silver nanoparticles, $1 \mathrm{ml}$ of the leaf extract was added to the $9 \mathrm{ml}$ of $1 \mathrm{mM}$ aqueous silver nitrate solution. The mixture was incubated in dark 
condition at room temperature. The visual color change in the reaction mixture from yellow to reddish brown was observed after $5 \mathrm{~min}$ with reference to control, which indicates the formation of silver nanoparticles. Further confirmation was done by spectrometric analysis.

\subsection{Optimization of various experimental parameters}

Several experimental parameters like effect of metal ion concentration, $\mathrm{pH}$ and different incubation time were evaluated for biosynthesis process using $A$. calcarata. The absorbance of resultant samples was measured at $420 \mathrm{~nm}$ using UV-Vis spectrophotometer.

\subsubsection{Effect of metal ion concentration}

To study the effect of concentration of silver nitrate solution on nanoparticle synthesis, various concentration of silver nitrate $(0.5-3 \mathrm{mM})$ was used. During the synthesis $9 \mathrm{ml}$ of each concentration $(0.5-3 \mathrm{mM})$ was taken in different test tubes. $1 \mathrm{ml}$ of leaf extract was added to each of test tubes and incubated in dark condition at room temperature. Synthesis of silver nanoparticles was confirmed by UV-Vis spectrometric analysis.

\subsubsection{Effect of $p H$}

To study the effect of $\mathrm{pH}$ on nanoparticle biosynthesis, synthesis process was carried out at various $\mathrm{pH}$ ranges from (4 to 11). Silver nitrate at optimum concentration obtained by previous study was used and all other parameters for biosynthesis process were remaining the same.

\subsubsection{Effect of contact time on nanoparticles biosynthesis}

To study the effect of incubation period, synthesis of nanoparticle was carried at different time intervals from 0 to $16 \mathrm{~h}$, absorbance of resulting solution was taken at $420 \mathrm{~nm}$ at various time intervals. Optimum silver nitrate concentration and $\mathrm{pH}$ was used from the previous experiments and other parameters were remaining the same.

\subsection{Characterization of silver nanoparticles synthesized under optimum condition \\ 2.6.1 UV-visible spectroscopy}

Initial characterization of the Ag nanoparticles was carried out using UV-visible spectroscopy. Reduction of silver ions to the silver nanoparticles was examined by measuring the surface plasmon resonance of the reaction mixture. The spectra were recorded on, Double Beam Spectrophotometer, 2203 at room temperature regulated at a resolution of $1 \mathrm{~nm}$ between 300 and $700 \mathrm{~nm}$ ranges. Optical density was taken at different wavelength ranging from 300 to $700 \mathrm{~nm}$ and plotted the values on a graph. Scanning was performed after reaction time ranging from $5 \mathrm{~min}$ to $24 \mathrm{~h}$.

\subsubsection{Dynamic light scattering (DLS) and Zeta potential analysis}

The particle size range of the nanoparticle with their polydispersity was analyzed using zetasizer instrument (Zetasizer Nano, Malvern UK). The size of the particle was measured by the time dependent fluctuation of scattering of laser light when particles were under gone to Brownian motion. With the help of this we can also analyze the size distribution pattern and the mean size of the particle inside the sample.

For measurements of zeta potential to infer about their stability of the colloidal AgNPs was analyzed via Zeta Sizer instrument (Malvern-Nano ZS 90). The sample was poured into sample holders of the instrument and data recorded.

\subsubsection{Fourier transform infrared spectroscopy (FTIR)}

Reaction mixture was centrifuged at $12,000 \mathrm{rpm}$ for $20 \mathrm{~min}$ to remove the biological biomass residues. Obtained pellet were redispersed in distilled water and then again centrifuge it. This step is repeated for $2-3$ times. Finally samples were dried and grinded with $\mathrm{KBr}$ pellets and then subjected to FTIR spectroscopy measurements. The measurements were carried out on a Thermo-Nicolet-Avatar 370 instrument in the different reflectance mode at a resolution of $4 \mathrm{~cm}^{-1}$ in $\mathrm{KBr}$ pellet.

\subsubsection{Inductively coupled plasma-optical emission spectrometry (ICP-OES)}

The technique is mainly used for the qualitative and quantitative determination of the metals and metalloids in the biological samples. The working principle of emission spectrometry (Perkin Elmer Optima 5300 DV ICP-OES) is based on the fact that atoms or ions in an excited state tend, to revert back to the ground state and in so doing emit characteristic wavelength and intensity of that light is proportional to the concentration of that particular element in the sample solution.

\subsubsection{Transmission electron microscopy (TEM)}

The morphology including their shape and size were determined by transmission electron microscopy (TEM CM 200 instrument). For TEM study sample is prepared by sonicated it first for $20 \mathrm{~min}$ and then a drop of it was placed on copper grid and it was allowed to dry in vacuum, resulting an image is produced from the introduction of the electron transmitted through the sample.

\subsubsection{X-ray diffraction pattern measurement}

The X-ray diffraction pattern of biosynthesised silver nanoparticles was performed on a diffractometer 
(Bruker AXSD8 Advance). Synthesized silver nanoparticle solution was cast onto glass slides, and operated at a voltage of $20 \mathrm{~mA}$ with $\mathrm{Cu}$, radiation of $1.5406 \mathrm{~nm}$ wavelengths. Scanning was done in the range of $2 \theta$ from $10^{\circ}$ to $90^{\circ}$. Size of synthesised nanoparticles was calculated by using Scherer's equation,

$$
\mathrm{D}=\mathrm{k} \lambda / \beta \cos \theta
$$

where $\mathrm{D}$ is average crystal size, $\mathrm{k}$ is Scherer coefficient (0.89), $\lambda$ is $X$-ray wavelength $(\lambda=1.5406 \mathrm{~nm}, \theta$ is Bragg's

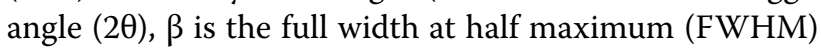
in radians.

\subsection{Bactericidal activity of synthesized silver nanoparticles}

The Ag nanoparticles synthesized by using leaf extract was tested for dose dependent antibacterial activities by agar well diffusion method against pathogenic bacterial strains E. coli, P. aeruginosa (Gram - ve), and S. aureus (Gram +ve). In brief, the pure cultures of bacteria were subcultured on nutrient agar media (NAM). Each strain was swabbed uniformly on the individual plates. Wells of $6 \mathrm{~mm}$ diameter were made on nutrient agar plates by using cork borer. Various volumes of Ag nanoparticles $(20,30$ and $50 \mu \mathrm{l})$ were added to the centre of the well. The streptomycin $(1 \mathrm{mg} / \mathrm{ml})$ and plant extract were used as a positive and negative control for the antibacterial assay. Inoculated plates were incubated at $37^{\circ} \mathrm{C}$ for $24 \mathrm{~h}$. After incubation, the different levels of zone of inhibition of bacteria were measured and recorded. The standard deviation was calculated using three replicates of experiments. The results of antibacterial activity were compared with control experiment.

\subsection{In vitro antioxidant activities of synthesized silver nanoparticles}

\subsubsection{DPPH free radical scavenging assay}

The DPPH free radical scavenging activity of synthesized silver nanoparticles and plant extracts were carried out by taking absorbance at $517 \mathrm{~nm}$ using UV-visible spectrophotometer according to the method reported by Govindappa et al. [18]. Activity in terms of percentage was calculated using the following equation

$$
\% \text { of antioxidant activity }=(\text { Ac }- \text { As }) / A c \times 100,
$$

where Ac is the absorbance of the control sample and As is the absorbance of test sample. The results were expressed in terms of percentage of radical scavenging activity using ascorbic acid as standard.

\subsubsection{Hydrogen peroxide scavenging assay}

The $\mathrm{H}_{2} \mathrm{O}_{2}$ scavenging activity was evaluated by the method describes by Bhakya et al. [19]. Different concentration of silver nanoparticles and plant extract were mixed with $50 \mu \mathrm{l}$ of $5 \mathrm{mM} \mathrm{H} \mathrm{H}_{2} \mathrm{O}_{2}$ solution and incubated at room temperature for $20 \mathrm{~min}$. Ascorbic acid was used as standard. Absorbance was measured at $610 \mathrm{~nm}$. Activity in terms of $\mathrm{H}_{2} \mathrm{O}_{2}$ scavenging was calculated using above mentioned (Eq. 1).

\subsection{Statistical analysis}

All the experiments were performed in triplicates and the results were expressed as mean \pm standard deviation. Significant levels were tested at $P<0.05$.

\section{Results and discussion}

In the present investigation we have demonstrated the biosynthesis of silver nanoparticles using leaf extracts of $A$. calcarata. Qualitative phytochemical analysis was performed to evaluate the phytoconstituents present in the leaf extracts. Effect of various experimental parameters on silver nanoparticle biosynthesis was also studied. Further, silver nanoparticles synthesized under optimum conditions were characterized by different analytical instruments. Bioactivity of synthesized silver nanoparticles were evaluated by antibacterial and antioxidant assay.

\subsection{Phytochemical screening}

To evaluate the various phyto-constituents in the leaf extract of $A$. calcarata using different solvent extracts, a series of qualitative phytochemical tests were performed. Phytochemicals present in the different solvent extracts of $A$. calcarata are shown in Table 1 and include primarily phytosterols, phenolic compounds, quinones and flavonoids. The aqueous $A$. calcarata leaf extract consist a high amount of flavonoids and phenolic compounds suggesting that these biomolecules are the key components for synthesis of these silver nanoparticles. Flavonoids and phenolic compounds are secondary plant metabolites and many of these have been shown to contain high levels of antioxidant potentials. These phytochemicals are reported as antioxidant or free radicals scavengers, because they contain hydroxyl groups in their structure which leads to the antioxidant activities [20]. Moreover phenolic compounds are considered as effective hydrogen donors, which make them excellent antioxidants. The biomedical applications and multiple pharmaceutical activities of flavonoids and phenolic compounds have also been reported for other plant species [21]. In plants some water soluble bioorganic compounds are present which were thought to be the key components for the reduction of Ag ions to nano sized Ag nanoparticles. Previous studies also reported that biomolecules present in the leaf extract of $A$. calcarata are phenolic compounds, 
Table 1 Phytochemical analysis of leaf extract of Alpinia calcarata in different solvents

\begin{tabular}{|c|c|c|c|c|c|}
\hline \multirow[t]{2}{*}{ Phytochemical test } & \multicolumn{5}{|c|}{ Different solvents } \\
\hline & Chloroform & Acetone & Methanol & Ethanol & Aqueous \\
\hline Alkaloids & - & - & - & + & - \\
\hline Saponins & - & - & + & - & - \\
\hline Phytosterol & - & - & + & - & + \\
\hline Flavonoids & + & + & - & ++ & ++ \\
\hline Quinones & - & + & + & + & + \\
\hline Tannins & - & - & - & + & + \\
\hline Phenolic compounds & - & + & + & + & ++ \\
\hline Glycosides & - & - & - & - & - \\
\hline Resins & - & - & + & + & - \\
\hline
\end{tabular}

(+) fairly present; (++) highly present; (-) absent

quinones, tannins, glycosides and flavonoids that are also considered as natural bioactive compounds [22, 23]. The biomolecules present in the leaf extract are that belongs to the phenol containing groups [24]. $\mathrm{Ag}^{+}$ have ability to form intermediate complexes with $-\mathrm{OH}$ or $\mathrm{C}=\mathrm{O}$ (Hydroxyl or carboxyl groups) present in the leaf extract as a key components, which subsequently involve reduction to $-\mathrm{COOH}$ forms and leads to bioreduction of $\mathrm{Ag}^{+}$to $\mathrm{Ag}$ nanoparticles [19].

\subsection{Biosynthesis of silver nanoparticles}

In aqueous medium silver nanoparticles appears brownish red in color due to surface plasmon vibrations [2]. When the aqueous plant extract was mixed with $1 \mathrm{mM} \mathrm{AgNO}_{3}$ solution, reaction started within few minutes, and the reaction color was observed in which yellowish plant extract solution changed into reddish brown color that confirms the formation of silver nanoparticles (Inset Fig. 1A). Similar color changes were observed by Ravichandran et al. [25] when they mixed the leaf extract of Atrocarpus altilis with the $\mathrm{AgNO}_{3}$ solution. Edison et al. [26] observed the similar color changes of the plant extract Terminalia cuneata after $72 \mathrm{~h}$ of incubation at dark condition. Nanoparticles are generally characterized by their size, shape, surface area and dispersity. Change in color was mainly due to the excitation of surface plasmon resonance in metal nanoparticles [27]. The change in color is also one of the significant evidence for formation of silver nanoparticles. Our results were also corroborated with previous studies [28-30], who reported the formation of silver nanoparticles using plant extracts. Variation in the time of bioreduction of is might be due to the differences in the activities of the enzymes present in plant extract.

\subsection{Optimization of various experimental parameters}

Optimization of experimental conditions is essential in order to achieve the optimum conditions for silver nanoparticles formation. The optimizing factors involved in this study were silver nitrate concentration, $\mathrm{pH}$ and incubation period.

\subsubsection{Effect of metal ion concentration}

Effect of various substrate concentrations in the reaction mixture was shown in (Fig. 2a). It is clear that they had an obvious influence on the biosynthesis of silver nanoparticles. A concentration of $1.5 \mathrm{mM}$ of silver nitrate was found to be optimum concentration for biosynthesis process. Whereas other concentrations $(2-3 \mathrm{mM})$ enable the synthesis of silver nanoparticles, but we have chosen the $1.5 \mathrm{mM}$ concentration due to their less toxicity as compared to the other concentrations. Previous reports also suggested that higher concentration of silver nitrate produces larger particle size [31]. It was also reported that when we increase the substrate concentration above than $3 \mathrm{mM}$, they are unstable and show aggregation and precipitation at the bottom of the reaction mixture.

\subsubsection{Effect of $\mathrm{pH}$}

To study the effect of the $\mathrm{pH}$ on nanoparticle biosynthesis we have selected a $\mathrm{pH}$ range of 4-11. Synthesized silver nanoparticles stability were determined by their corresponding absorbance at $420 \mathrm{~nm}$ at $\mathrm{pH}$ from 4 to 11 (Fig. 2b). An increase in the absorbance with increase in $\mathrm{pH}$ suggested that alkaline reaction condition was more appropriate for silver nanoparticle biosynthesis. However, when we increase the $\mathrm{pH}$ from 9 to 11 , aggregation of nanoparticles was observed. Previous studies also show that optimal $\mathrm{pH}$ for silver nanoparticle biosynthesis has varied by plant species. Spectral responses of individual nanoparticles are related with 

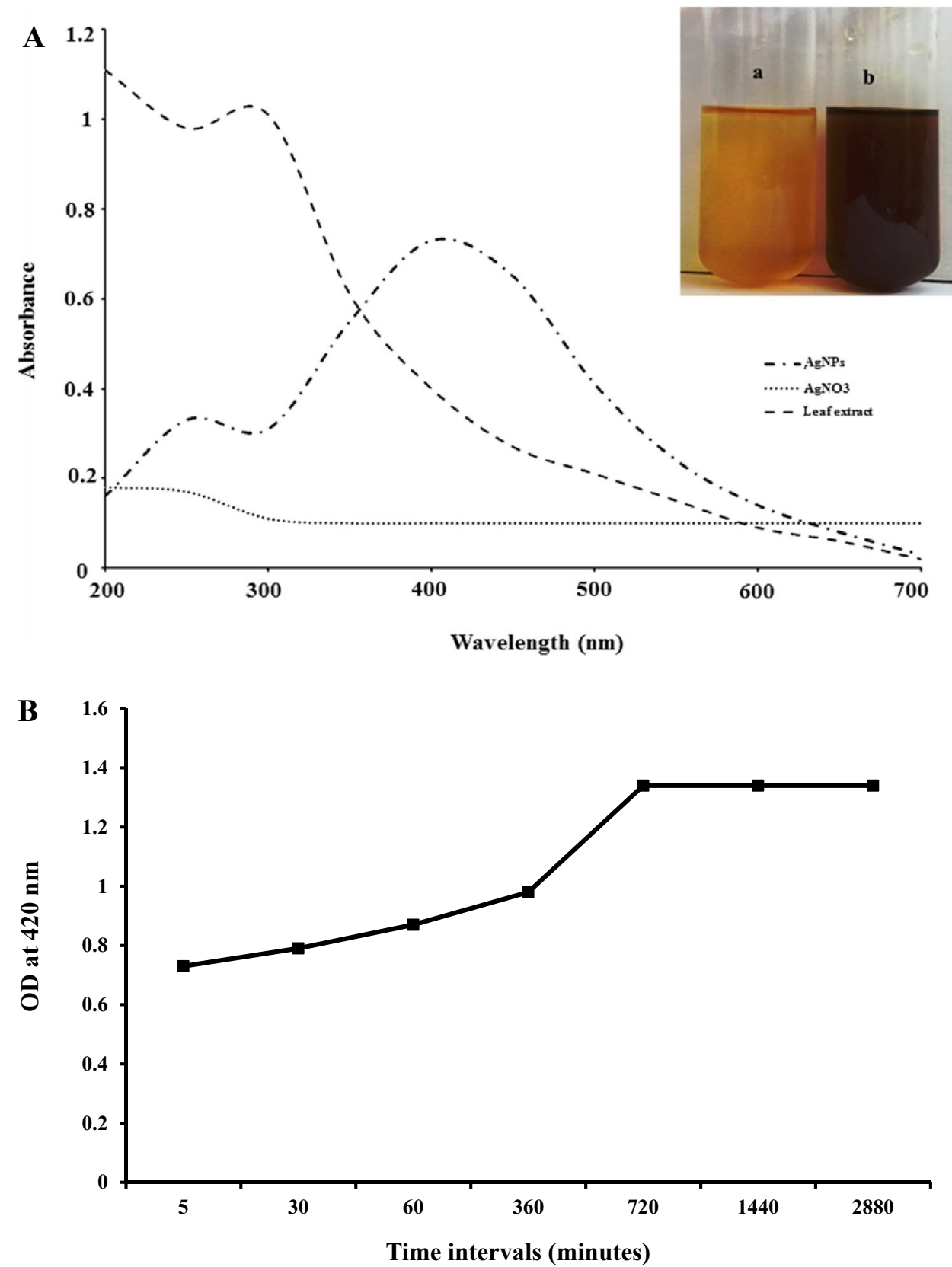

Fig. 1 A UV-Visible spectrum of synthesized silver nanoparticles [inset: change in color of the solution confirming the formation of silver nanoparticles]. (a) Plant extract and (b) synthesized silver nanoparticles. B Color intensity at $420 \mathrm{~nm}$ for silver nanoparticles synthesized by A. calcarata leaf extract during different time intervals

the size and shape of the nanoparticles. It has been reported that change in $\mathrm{pH}$ affects the size and shape of the particles as $\mathrm{pH}$ has the ability to change of biomolecules that might affect their reduction as well as stability. Our results were also shows similarity with the findings of Prathna et al. [32].

\subsubsection{Effect of contact time on nanoparticles biosynthesis}

Figure 2c shows the effect of various incubation periods (time) on biosynthesis of silver nanoparticles. As we increase the incubation period the absorbance value was also increases up to $12 \mathrm{~h}$, but thereafter they did not show any increase. In another study Pugazhendhi et al. 

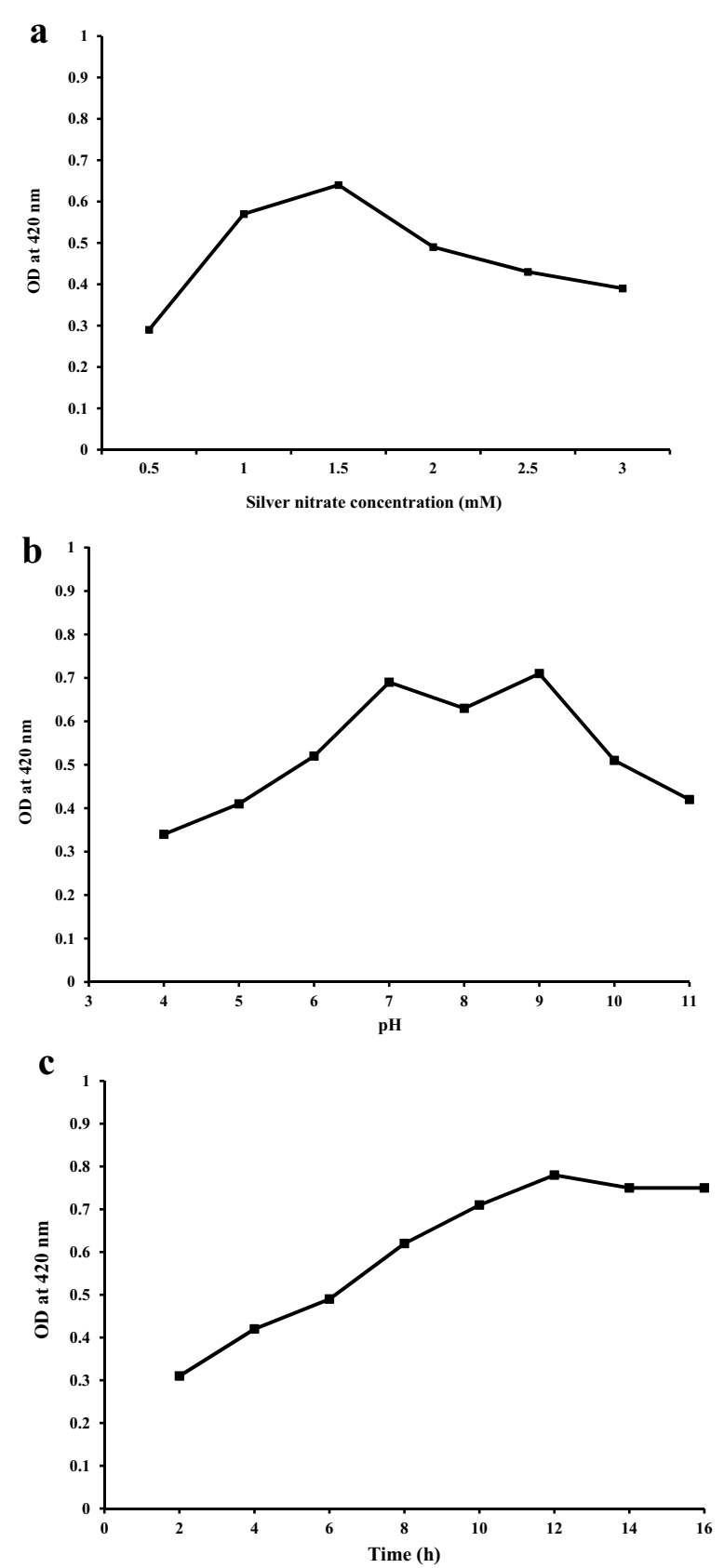

Fig. 2 Optimization of several experimental parameters on biosynthesis of silver nanoparticles (a). Effect of metal ion concentration on silver nanoparticle biosynthesis (b). Effect of $\mathrm{pH}$ on silver nanoparticle biosynthesis (c). Effect of time (incubation period) on silver nanoparticle biosynthesis
[23] A. calcarata shows the formation of silver nanoparticles after $24 \mathrm{~h}$ of incubation.

\subsection{Characterization of synthesized silver nanoparticles 3.4.1 UV-Vis spectroscopy}

UV-Vis spectroscopy analysis is used to determine the formation and stability of silver nanoparticles in the aqueous solution [23]. In aqueous suspension the size and shape of silver nanoparticle is generally recognized with UV-visible spectroscopy. The formation of silver nanoparticles was observed using UV-visible spectroscopy 200-700 nm wavelength range. In our result highest peak was observed at $420 \mathrm{~nm}$ (Fig. 1A), which was found to be specific for the biosynthesis of silver nanoparticles. The reaction mixture showed a single SPR band, which confirms the spherical shape of silver nanoparticles [3], which was further confirmed by TEM micrographs. The UV-Vis spectra also showed that the silver nanoparticles formed rapidly within $10 \mathrm{~min}$ and remained stable even after $48 \mathrm{~h}$ (Fig. 1B). Intense plasmon band was observed after 5 min between 400 and $430 \mathrm{~nm}$, which indicates its high reducing efficiency. No change in absorbance was recorded after $48 \mathrm{~h}$ of incubation, confirming the complete reduction of $\mathrm{Ag}^{+}$ions to silver nanoparticles. Optical absorbance spectrum of metal nanoparticles is due to SPR (surface plasmon resonance), which leads to a shift towards the red or blue ends depending upon the shape and size of the particle, surrounding medium and state of agglomeration [33]. Stability of the synthesized silver nanoparticles was studied by, measuring its intensity by UV-Vis spectrophotometer over a period of 3 months in same reaction conditions. No significant change in the absorbance was observed, which confirmed its stability over a longer period (data not shown here). Synthesis time of silver nanoparticle is quite shorter as compared to previously reported studies with plant extract $[29,34$, 35].

\subsubsection{Dynamic light scattering (DLS) and Zeta potential analysis}

The analysis was used to analyze the size distributions and specifically measurement of monodispersity in aqueous solution. The size distribution histogram of particle size analyzer showed the Z-average diameter of $84.37 \mathrm{~nm}$ with polydispersity index (0.252) for biosynthesised silver nanoparticles (Fig. 3a). The size showed particle size analysis is quite larger than the size reported by TEM 
analysis. The variations in the results are mainly due to the process involved in the sample preparation [36]. It has been reported that the value of polydispersity index are less than 0.7 which confirms the quality of nanoparticles to be good. DLS is mainly used to analyze the quantitative size distributions as well as a more precise quantity of monodispersity in colloidal solution. Result obtained from DLS analysis shows more polydispersity and larger particle size as compared to result obtained from TEM analysis and this is mainly due to the fact that DLS analysis measured size also included the size of biomaterials that covers the surface of silver nanoparticles [19].

The surface zeta potential values of AgNPs were measured to be slightly negative and were $-19.4 \mathrm{mV}$ (Fig. 3b). Duan et al. [37] reported that AgNPs mainly exhibit negative charge. The possible cause of the negative surface charges on synthesized AgNPs is may be due to the absorption of free nitrate ions present during the reduction of $\mathrm{AgNO}_{3}$ [38]. The negative charge of AgNPs prevents them from agglomeration and increases their stability, as well as help to enhance their antimicrobial property. Zeta potential is mainly used for the quantification of the magnitude of charge which is a key indicator of the stability of colloidal dispersions. The magnitude of zeta potential indicates the degree of electrostatic repulsion between adjacent, similarly charged particles in dispersion. When the value for zeta potential is small, attractive force may causes the repulsion and may break and flocculate the dispersion. Nanoparticles have very small diameter and are highly energetic, this makes them highly unstable. So that particles undergo agglomeration/ aggregation to stabilize themselves and also develop certain charges on their surface which contributes to their stabilization. Zeta potential has direct relation with the stability of a structure.

\subsubsection{Fourier transform infrared spectroscopy (FTIR)}

FTIR spectrum shows the possible biomolecules present in the leaf extract which might be involved in the reduction of silver ions. FTIR spectral measurements were studied at a resolution of $4 \mathrm{~cm}^{-1}$ to characterize the potential functional groups of biomolecules in the leaf extracts responsible for reduction and stabilization of bio-reduced silver nanoparticles. In our results the FTIR analysis revealed (Fig. 4) different absorption peak at $546.04 \mathrm{~cm}^{-1}, 1042.18 \mathrm{~cm}^{-1}, 1353.65 \mathrm{~cm}^{-1}, 1456.41 \mathrm{~cm}^{-1}$, $1636.72 \mathrm{~cm}^{-1}, \quad 1813.89 \mathrm{~cm}^{-1}, \quad 2076.48 \mathrm{~cm}^{-1}$, $2531.19 \mathrm{~cm}^{-1}$, and at $3456.63 \mathrm{~cm}^{-1}$, assigned to the $(\mathrm{C}-\mathrm{Br}),(\mathrm{C}-\mathrm{O}$ stretch), ( $\mathrm{N}-\mathrm{O}$ stretching), (-C-H bending) alkane, $(\mathrm{C}=\mathrm{C})$ alkene, $(\mathrm{C}=\mathrm{O})$ carbonyl stretch, $(\mathrm{C}=\mathrm{C})$ stretch, $(\mathrm{O}-\mathrm{H}$ stretch $)$ acid and $(\mathrm{N}-\mathrm{H})$ stretch or bend respectively. Sivaraman et al. [39] reported that the tannic acid which is a polyphenol and it's a plant derived compound can be effectively reduces the silver nanoparticles. Water soluble organic compounds present in the plant materials were act as a reducing agent of silver ions to nano sized silver particles. The results indicate that the flavonoids, phytosterols, and phenolic compounds present in the plant extract play a major role in formation of silver nanoparticles in their respective ions in solution. Oxidation - reduction potential of phenolic compounds offer them to serve as a reducing agent, hydrogen donor, singlet oxygen quencher and metal ion chelators. The sharp peak at $2076.48 \mathrm{~cm}^{-1}$ and $3456.63 \mathrm{~cm}^{-1}$ attributed to the $(\mathrm{C}=\mathrm{C})$ alkyne and $(\mathrm{N}-\mathrm{H})$ amide functional groups, which indicates the presence of various aromatic and carbonyl groups of the proteins and plant metabolites present in the leaf extract that may be involved in the bioreduction process [40]. The position of these absorption bands were comparable to the phytochemicals reported in the $A$. calcarata leaf extract from Table 1 . Hence, it can be concluded that the phytochemicals present in the leaf of $A$. calcarata is responsible for the reduction and stabilization of the silver nanoparticles. Similarly Vasantharaj et al. [41] reported that the phyto compounds like amides, phenols and aromatic compounds present in plant extract have strong binding efficiency with silver and also play a crucial role in reduction and stability of silver nanoparticles from Ag ions. On the basis of this we can assume that these biomolecules play an important role in the bioreduction as well as in the stabilization of metal nanoparticles [42]. FTIR results suggest that in the aqueous leaf extract water soluble phenolic groups are present which serve as a capping and stabilizing agents for silver nanoparticles, although the exact mechanism of nanoparticle formation is still unknown. Philip et al. [43] reported that flavonoids, alkaloids and polyphenols present in leaf extract of Murraya koenigii leaf responsible for reduction and stabilization of the synthesized gold and silver nanoparticles.

\subsubsection{Inductively coupled plasma-optical emission spectrometry (ICP-OES)}

The concentration of synthesized silver nanoparticles in the aqueous medium was determined by ICP-OES analysis. In this study we found that leaf extract of $A$. calcarata produces about $24.81 \mathrm{ppm}$ of silver nanoparticles, per litre of culture filtrate when $1.5 \mathrm{mM}$ silver nitrate was added.

\subsubsection{Transmission electron microscopy (TEM)}

Images of TEM analysis of silver nanoparticles revealed that well dispersed and highly crystalline silver nanoparticles were formed (Fig. 5a) and are mostly roughly spherical in shape with dark edges. Figure $5 b$ shows the histogram pattern of synthesized silver nanoparticles. 
$\mathbf{a}$

\section{Z-Average (d.nm): 84.37}

Pdl: 0.252

Intercept: 0.855

Result quality: Good

\section{Size (d.nm)}

Peak 1:117.7

Peak 2: 11.44

Peak 3: 0.000

$\begin{array}{cc}\text { \% Intensity } & \text { Width (d.nm) } \\ 98.0 & 65.14 \\ 2.0 & 2.985 \\ 0.0 & 0.000\end{array}$

Size Distribution by Intensity

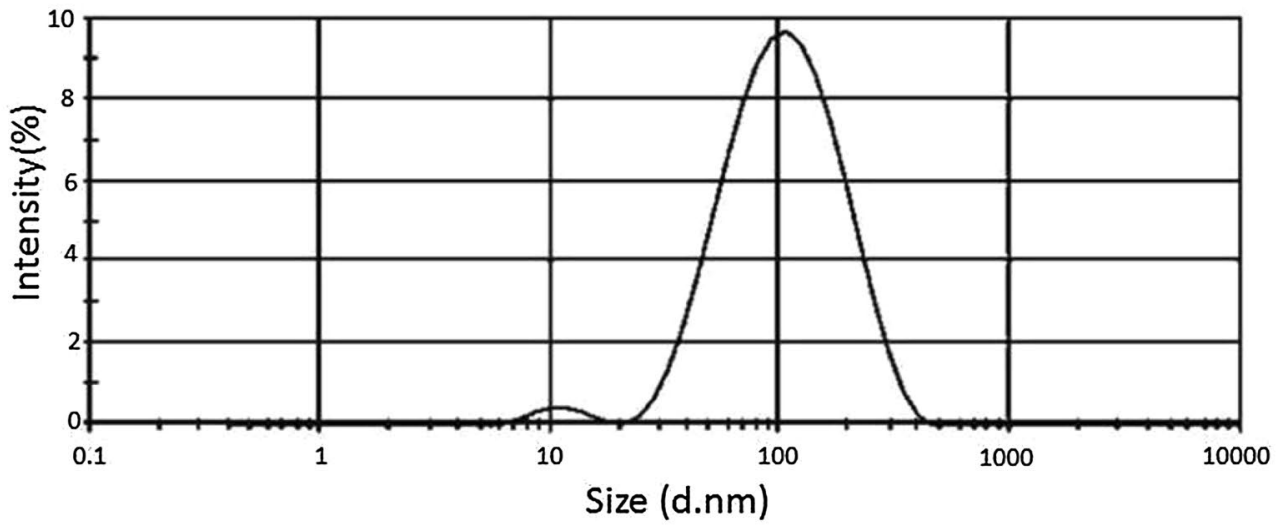

b

Results

Zeta Potential (mV): - 19.4

Zeta Deviation $(\mathrm{mV}): \mathbf{6 . 8 0}$

Conductivity (mS/cm): $\quad 0.365$

Result quality: Good

Zeta Potential Distribution

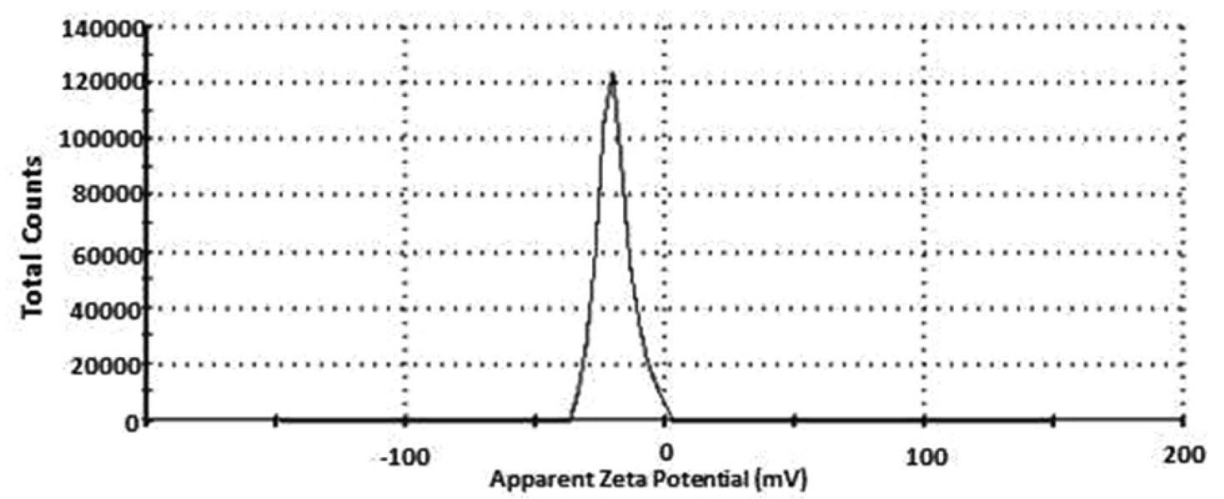

Fig. 3 a DLS size distribution pattern and $\mathbf{b}$ Zeta potential analysis of synthesized silver nanoparticles

The average size of the silver nanoparticles was found to be in range of 5-60 $\mathrm{nm}$ with average diameter of $27.17 \mathrm{~nm}$. The SAED (selected area electron diffraction) pattern of synthesized nanoparticles was also shown in the inset of (Fig. 5a). A circular ring was observed which shows the crystalline nature of the silver nanoparticles. The size and shape of the nanoparticles are important as their applications are dependent on their size and shape. Similar results were also obtained by Bar et al. [44] who synthesized the spherical shape silver nano crystals with 


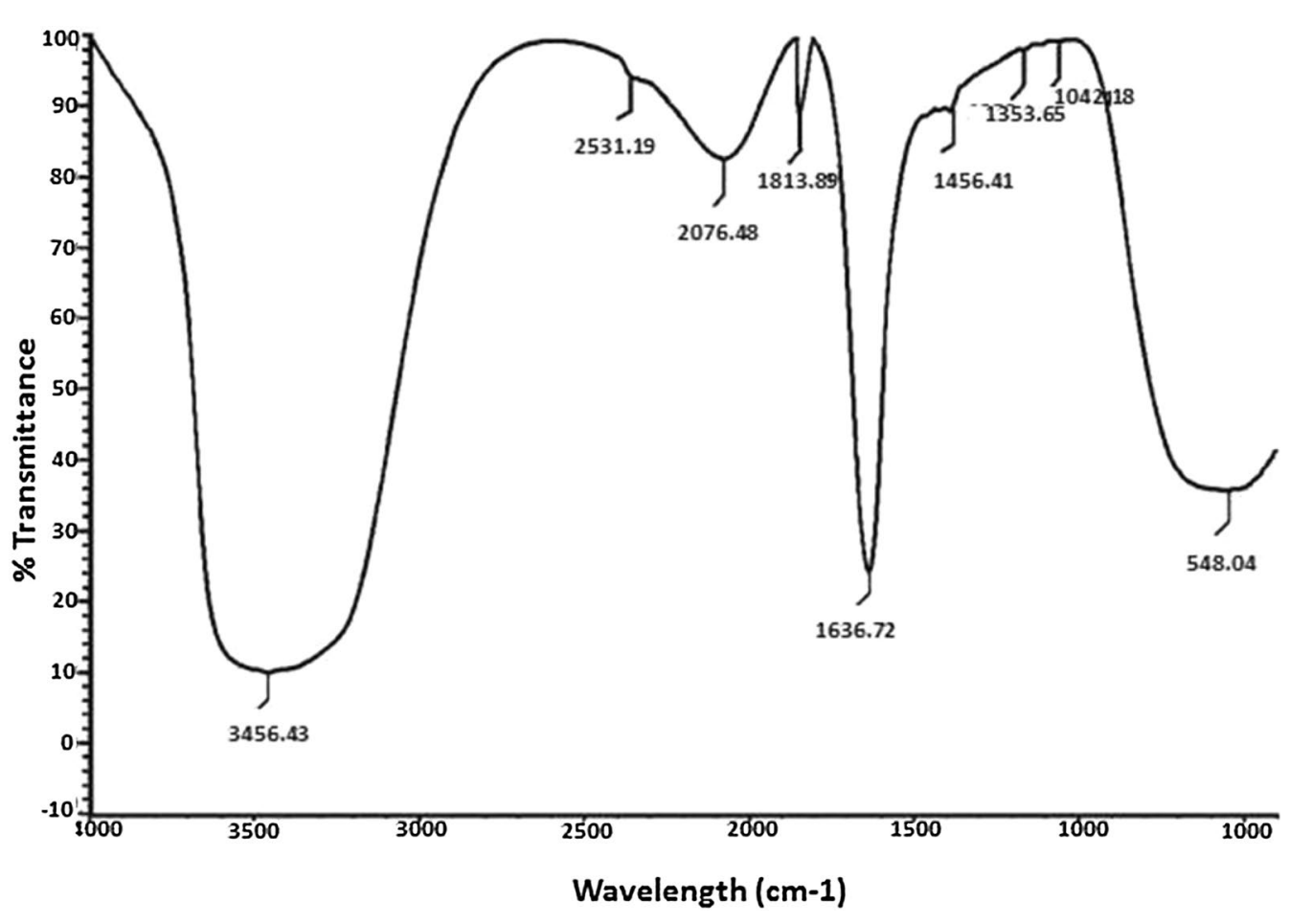

Fig. 4 FTIR spectrum of synthesized silver nanoparticles

average size in between range of $15-50 \mathrm{~nm}$ using latex of Jatropha curcas shape. In TEM micrograph it was also found that the edged of the synthesized silver nanoparticles were lighter than the centre, suggesting the presence of biomolecules like protein, polyphenols and flavonoids in leaf extract, that act as a capping agent and prevent their aggregation [23]. This type of inherent capping offers the additional benefits of the stability in the green chemistry synthesis [45]. Our results were also in agreements with the earlier reports [46-48].

\subsubsection{X-ray diffraction analysis (XRD)}

$X R D$ is mainly used for the phase identification and characterization of crystalline nature of synthesized silver nanoparticles. XRD pattern of synthesized silver nanoparticles are shown in Fig. 6. Results of XRD analysis indicate that the structure of silver nanoparticles is face-centred cubic (FCC). Additionally, in our results the XRD peaks at $2 \theta$ of $28.17^{\circ}, 33.31^{\circ}, 44.12^{\circ}, 54.12^{\circ}$ and $77.21^{\circ}$ could be attributed to the (220), (122), (111), (231) and (331) crystallographic planes. Thus, from the XRD analysis results it was clear that synthesized silver nanoparticles were crystalline in nature. Similar results were reported for Ziziphora tenuior [49], Citrus limon, Citrus sinensis and Citrus reticulate [50] and
Abelmoschus esculentus [51]. The XRD patterns showed here are consistent with earlier reports [52-54]. Sharp peaks of XRD profile clearly indicate the cubic crystalline nature of the synthesized silver nanoparticles. Similarly Yoon et al. [54] carried out a research and they also found the peaks at $28^{\circ}$ and $32^{\circ}$ in XRD diffractogram of fungal based silver nanoparticles.

\subsection{Antibacterial activity of synthesized silver nanoparticles}

The susceptibility of pathogenic bacteria to silver nanoparticles showed in Table 2. Zone of inhibition of standard antibiotics like streptomycin, plant extract and various volumes of silver nanoparticles were showed in Fig. $7 \mathrm{a}, \mathrm{b}$. Volumes of silver nanoparticles vary viz, $10 \mu \mathrm{l}$, $30 \mu \mathrm{l}$ and $50 \mu \mathrm{l}$. The results showed that the silver nanoparticles had efficient antibacterial activity against Grampositive and Gram-negative bacteria. The leaf extract of A. calcarata showed significantly less activity against all the test pathogens as compare to the silver nanoparticles synthesized from leaf extract. This indicates that the biological activity of leaf extract of $A$. calcarata increased when amended with silver, which means the silver nanoparticle produced with $A$. calcarata showed good antimicrobial activity. Although silver nitrate showed a moderate activity against all the test pathogens, but due 

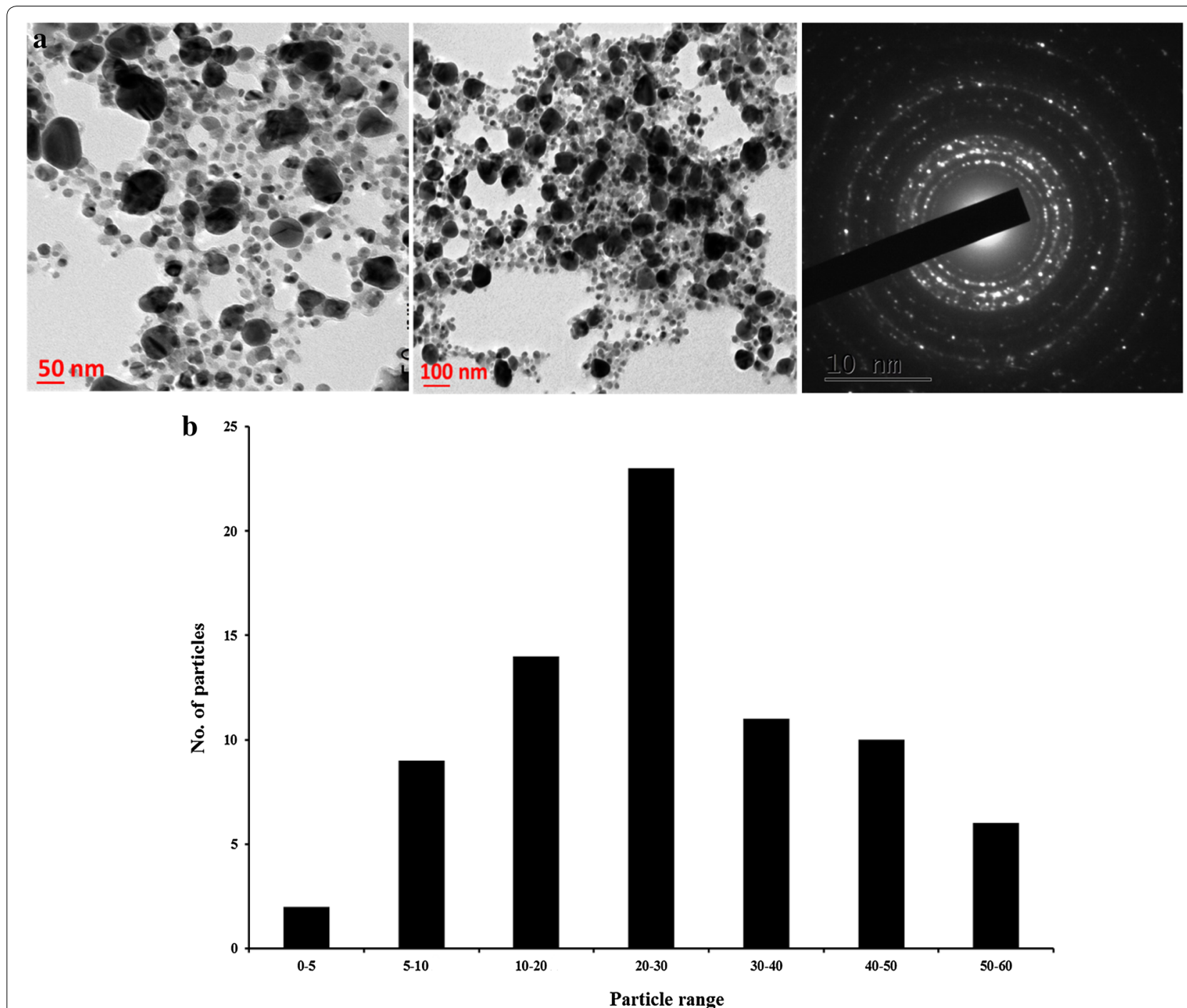

Fig. 5 a TEM micrograph showing size of silver nanoparticles at 50 and100 nm scales and SAED pattern. b Particle size histogram of synthesized silver nanoparticles

to its high toxicity against human cells, its effect was found to be insignificant. Interestingly in our results synthesized silver nanoparticles showed maximum antibacterial activity against $P$. aruginosa and E. coli. (Gram - ve bacteria) as compare to $S$. aurueus (Gram +ve bacteria). The result might be due to the differences in cell wall structure of Gram +ve and Gram -ve bacteria. According to Chaloupka et al. [55] the Gram +ve bacteria consist a thick layer of peptidoglycan which consist linear polysaccharide chain cross linked by short peptides, so that forming a rigid cellular structure and thus leads to difficult penetration of the silver nanoparticles. While increasing the concentration of silver nanoparticles, zone of inhibition also increases. Control shows no zone of inhibition, which indicates that the antibacterial properties is due to synthesized silver nanoparticles. Lok et al. [56] reported that bacterial cell membrane and plasma were damaged by silver nanoparticles which lead to exhaustion of the intracellular adenosine triphosphate. Elgorban et al. [57] were also studied the antibacterial effect of silver nanoparticles was depend on shape and size. Nanoparticles having size within range of 1-10 nm can attach to the cell surface and effectively damage the permeability and respiratory functions [58]. Though the antimicrobial activity by silver nanoparticle is very prominent, but their mode of action is still debatable. Sondi and Sondi [59] proposed that silver nanoparticles has the 


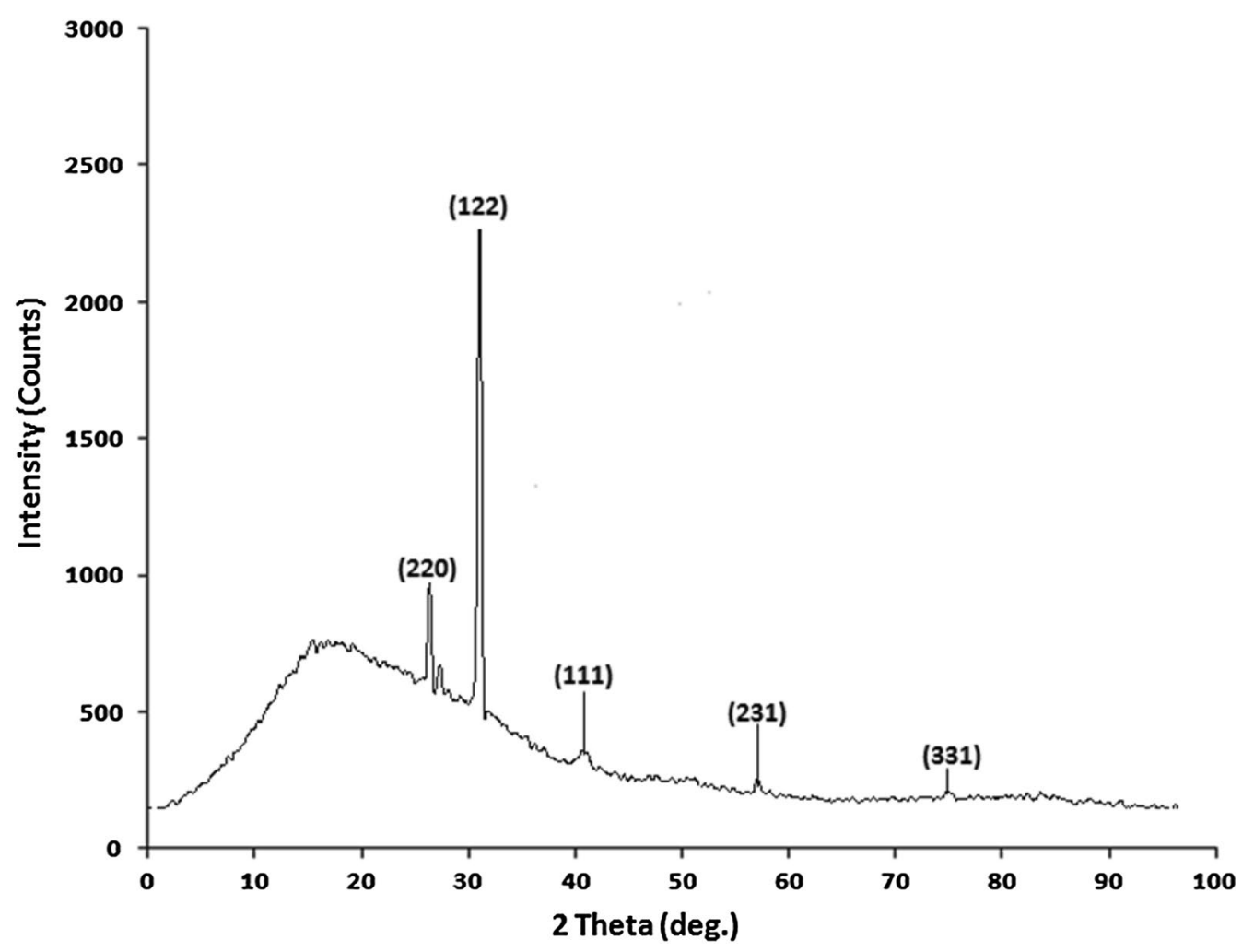

Fig. 6 XRD pattern of the synthesized silver nanoparticles from A. calcarata

Table 2 Antibacterial activity of synthesized silver nanoparticles

\begin{tabular}{|c|c|c|c|c|c|c|}
\hline \multirow[t]{3}{*}{ Bacterial strains } & \multicolumn{6}{|c|}{ Zone of inhibition (mean \pm SD in $\mathrm{mm}$ ) } \\
\hline & \multirow[t]{2}{*}{$\mathrm{AgNO}_{3}(1 \mathrm{mM})$} & \multirow{2}{*}{$\begin{array}{l}\text { Streptomycin } \\
(1 \mathrm{mg} / \mathrm{ml})\end{array}$} & \multirow[t]{2}{*}{ Plant extract $(50 \mu \mathrm{l})$} & \multicolumn{3}{|c|}{ Synthesized AgNPs } \\
\hline & & & & $10 \mu \mathrm{l}$ & $30 \mu \mathrm{l}$ & $50 \mu \mathrm{l}$ \\
\hline E. coli & $12.17 \pm 0.34$ & $24.12 \pm 0.61$ & $2.87 \pm 0.16$ & $9.13 \pm 0.52$ & $22.13 \pm 0.54$ & $27.70 \pm 0.31$ \\
\hline S. aureus & $15.06 \pm 0.12$ & $19.54 \pm 0.73$ & $5.38 \pm 0.61$ & $13.41 \pm 0.33$ & $17.52 \pm 0.37$ & $22.43 \pm 0.45$ \\
\hline P. aeruginosa & $10.11 \pm 0.43$ & $27.42 \pm 0.57$ & $3.67 \pm 0.35$ & $17.09 \pm 0.42$ & $21.17 \pm 0.63$ & $29.14 \pm 0.63$ \\
\hline
\end{tabular}

$S D$ standard deviation

ability to attach with the bacterial cell membranes that causes change in bacterial cell membrane structure and leads to the formation of 'pits' where they accumulate. In another report it was supposed that silver nanoparticles releases silver ions that interact with the thiol groups of enzymes and leads to the inactivation of most of the respiratory chain enzymes due to the formation of reactive oxygen species (ROS) which causes the apoptosis of bacterial cell [60-63].

A number of reports available that shows that silver have been permanently utilized to treat or inhibit a wide range of disease caused by both Gram positive and Gram negative bacteria [64]. Results from previous studies also support the antibacterial activity of silver nanoparticles [65]. No zone of inhibition was shown in case of control. Recently nanoparticles has been used as an interesting alternative method to antibiotics and supposed to have a high potential in curing several bacterial diseases in human. In recent years silver nanoparticles have attracted significant attention especially in antimicrobial activity $[66,67]$.

Similar study was carried out by Paszek et al. [68], during their study they reported that the high antibacterial activity of silver nanoparticles is due to the release of silver cations from silver nanoparticles that act as reservoirs for the $\mathrm{Ag}^{+}$bactericidal agent. Silver nanoparticles 


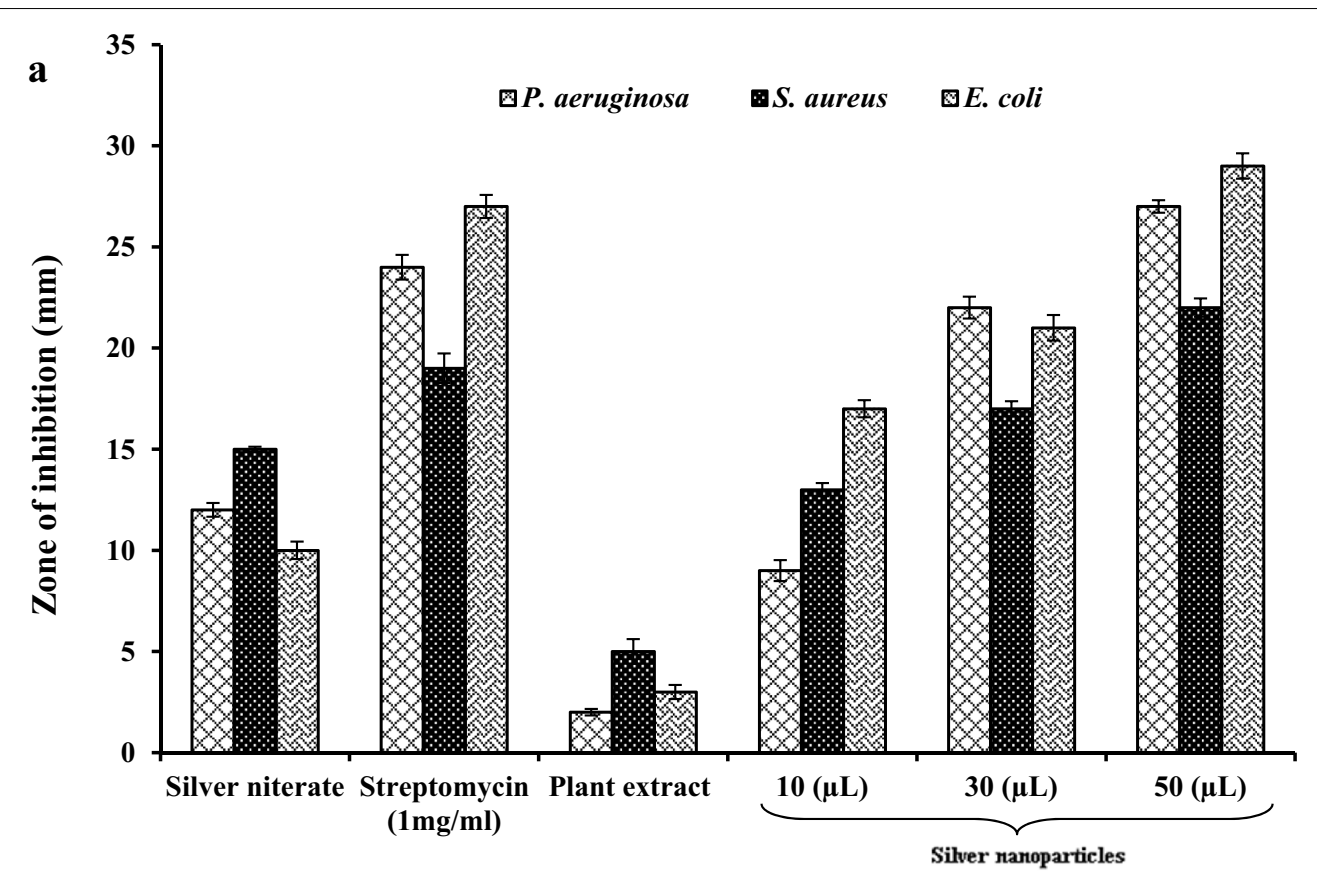

Test samples

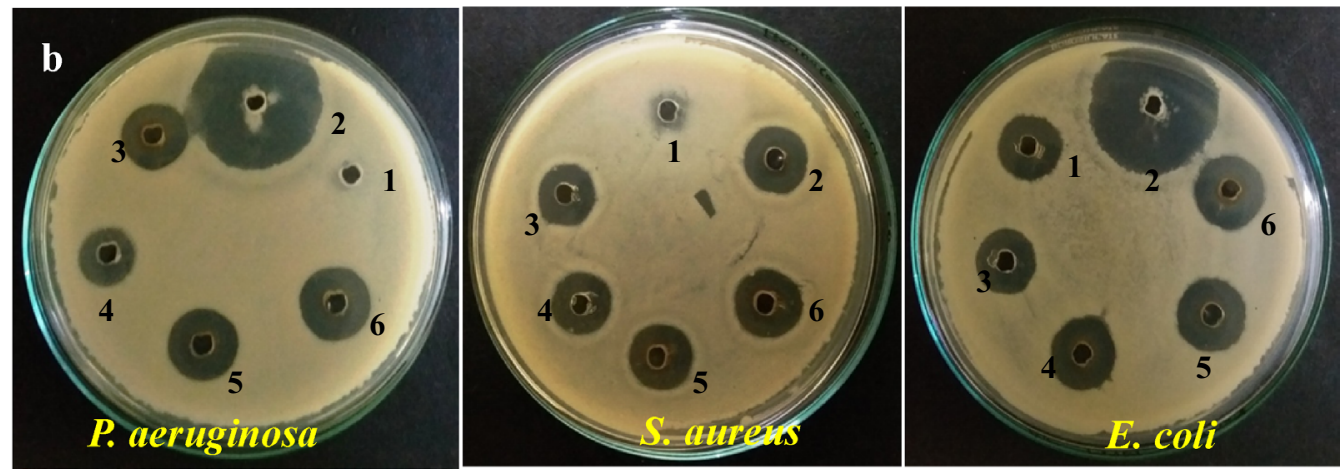

Fig. 7 a Antibacterial activity of silver nanoparticles against various pathogenic bacterial strains. b Zone of inhibition (1) Plant extract; (2) Streptomycin; (3) Silver nitrate; (4) $10 \mu \mathrm{l}$ silver nanoparticles; (5) $30 \mu \mathrm{l}$ silver nanoparticles; (6) $50 \mu \mathrm{l} \mathrm{silver} \mathrm{nanoparticles}$

synthesized from various plant extracts were reported for potent bactericidal activity [69-71].

Results of this study strongly recommended that silver nanoparticle synthesized from $A$. calcarata exhibit potential antibacterial activity against disease causing pathogenic strains of bacteria and hence can be used as an antibiotic or may be used for the development of nano based antibacterial formulations.

\subsection{Antioxidant activities of synthesized silver nanoparticles}

$\mathrm{DPPH}$ is a stable free radical at room temperature and accepts an electron or hydrogen radical to form stable diamagnetic molecules [71, 72]. DPPH free radical scavenging activity has been used extensively for determining antioxidants such as polyphenols. The free radical scavenging activity of silver nanoparticles was assessed by observing the visual color changes from purple to yellow after reduction, while the control does not show any color changes. As compared to the standard ascorbic acid, synthesized silver nanoparticles shows effective DPPH scavenging activity (Fig. 8a). It has been also revealed that the antioxidant potentials of silver nanoparticles increase in a dose dependent manner. Instead of this silver nanoparticle also shows more inhibition with $90 \%$ scavenging activity of DPPH. Our results were corroborated with Ragini et al. [73], who reported the free radical scavenging activity of Shorea tumbuggaia, and 

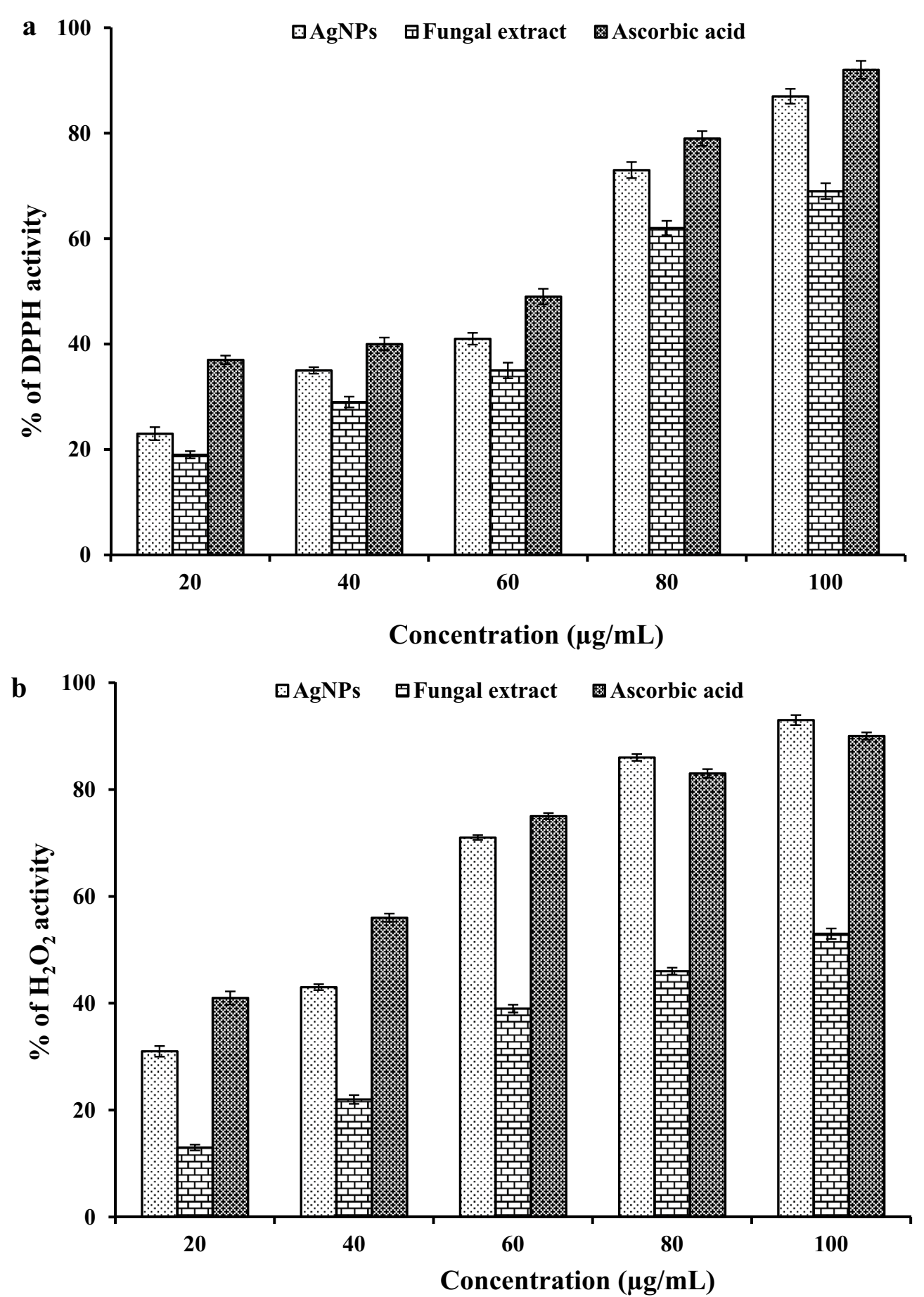

Fig. 8 Antioxidant activities of synthesized silver nanoparticles. a DPPH free radical scavenging activity. $\mathbf{b} \mathrm{H}_{2} \mathrm{O}_{2}$ scavenging activity

found $79.50 \%$ scavenging activity at a $100 \mu \mathrm{g} / \mathrm{ml}$ concentration. Various plant extract exhibit efficient antioxidant activities due to their phytochemicals, majorly incudes phenols and flavonoids [74].
The $\mathrm{H}_{2} \mathrm{O}_{2}$ scavenging activity of silver nanoparticles was quantitatively analyzed by using spectrophotometer and is shown in (Fig. 8b). As we know that hydroxyl radical is a highly reactive free radical formed in biological system and has been used as a highly damaging 
species in free radical pathology, having ability to damage a wide range of molecules like proteins, DNA, lipids etc. [75]. Results of present study showed that silver nanoparticles exhibited potential reducing power as compare to ascorbic acid. It has been reported that in the presence of $\mathrm{H}_{2} \mathrm{O}_{2}$ silver nanoparticles can hydroxyl radicals (reactive oxygen species). The free radical scavenging activity of silver nanoparticles are might be due to the presence of several phyto-constituents that have ability to donate the hydrogen atom in their $\mathrm{OH}$ groups. Results also resembles with earlier reports on antioxidant activity of leaf extract of Erythrina suberosa (Roxb.) [71]. The result obtained from this experiment also recommends the applications of silver nanoparticles as natural antioxidant agent for several health preservation against various oxidative stresses related with degenerative diseases.

\section{Conclusions}

The present study revealed the rapid fabrication of silver nanoparticles using leaf extract of $A$. calcarata. Silver nanoparticles formation was achieved within 10 min, which was confirmed by UV-Vis spectroscopy analysis that showed a sharp peak at $420 \mathrm{~nm}$ confirming the formation of silver nanoparticles. The effects of various experimental parameters played a major role in the biosynthesis and size control of the particles. FTIR results suggested that the biomolecules like the secondary metabolites present in the plant leaves are responsible for the reduction and stabilization of nanoparticles. TEM micrograph of synthesized silver nanoparticles showed spherical shaped nanoparticles with average particle size $27 \mathrm{~nm}$. DLS analysis showed that synthesized nanoparticles were well dispersed. XRD analysis concluded that synthesized nanoparticles were highly crystalline in nature. Antibacterial and antioxidant studies revealed that the synthesized Ag nanoparticles have potential bactericidal activities against all the selected pathogenic strains of bacteria and they also show efficient free radical scavenging activity. Hence this green chemistry principle towards the synthesis of silver nanoparticles have several benefits like rapid, convenient, facile and ease to scale up etc. Future prospects may include the formulation of nanomedicines against several human and veterinary pathogens by using such plant extracts and to develop studies in the interface between biology and material structural science.

\section{Authors' contributions}

PK and SKS design and wrote the manuscript. DKS, RKY and LK helped in performing the experiment. All authors read and approved the final manuscript.

\section{Acknowledgements}

The authors are thankful to SAIF IIT Madras for ICP-OES analysis, RGPV, Bhopal for DLS analysis, BIT Mesra for Zeta potential analysis, SAIF IIT Bombay for TEM analysis, STIC SAIF Cochin for FTIR and XRD analysis. The authors also like to acknowledge Head, Department of Botany, Guru Ghasidas Vishwavidyalaya, Bilaspur, Chhattisgarh, for providing lab facilities to carry out this work.

\section{Competing interests}

The authors declare that they have no competing interests.

\section{Consent for publication}

Not applicable.

Ethics approval and consent to participate

Not applicable.

\section{Funding}

Funding for this work has been received from the GGV VRET fellowship Registration Number: 145081604

\section{Publisher's Note}

Springer Nature remains neutral with regard to jurisdictional claims in published maps and institutional affiliations.

Received: 7 July 2018 Accepted: 19 November 2018

Published online: 06 December 2018

\section{References}

1. A. Chahardoli, N. Karimi, A. Fattahi, Nigella arvensis leaf extract mediated green synthesis of silver nanoparticles: Their characteristic properties and biological efficacy. Adv. Powder Technol. 29(1), 202-210 (2018)

2. V. Ahluwalia, S. Elumalai, V. Kumar, S. Kumar, R.S. Sangwan, Nano silver particle synthesis using Swertia paniculata herbal extract and its antimicrobial activity. Microb. Pathog. 114, 402-408 (2018)

3. C. Krishnaraj, E.G. Jagan, S. Rajasekar, P. Selvakumar, P.T. Kalaichelvan, N. Mohan, Synthesis of silver nanoparticles using Acalypha indica leaf extracts and its antibacterial activity against water borne pathogens. Colloids Surf. B 76(1), 50-56 (2010)

4. J.R. Morones, J.L. Elechiguerra, A. Camacho, K. Holt, J.B. Kouri, J.T. Ramírez, M.J. Yacaman, The bactericidal effect of silver nanoparticles. Nanotechnology 16(10), 2346 (2005)

5. S. Ahmed, M. Ahmad, B.L. Swami, S. Ikram, A review on plants extract mediated synthesis of silver nanoparticles for antimicrobial applications: a green expertise. J. Adv. Res. 7(1), 17-28 (2016)

6. P.K. Stoimenov, R.L. Klinger, G.L. Marchin, K.J. Klabunde, Metal oxide nanoparticles as bactericidal agents. Langmuir 18, 6679-6686 (2002)

7. M.A. Rahman, M.S. Islam, Alpinia calcarata Roscoe: a potential phytopharmacological source of natural medicine. Pharmacogn. Rev. 9(17), 55 (2015)

8. R. Perveen, F. Islam, J. Khanum, T. Yeasmin, Preventive effect of ethanol extract of Alpinia calcarata Rosc on Ehrlich's ascitic carcinoma cell induced malignant ascites in mice. Asian Pac. J. Trop. Biomed. 5(2), 121-125 (2012)

9. G. Bagherzade, M.M. Tavakoli, M.H. Namaei, Green synthesis of silver nanoparticles using aqueous extract of saffron (Crocus sativus L.) wastages and its antibacterial activity against six bacteria. Asian Pac. J. Trop. Biomed. 7(3), 227-233 (2017)

10. A. Tripathy, A.M. Raichur, N. Chandrasekaran, T.C. Prathna, A. Mukherjee, Process variables in biomimetic synthesis of silver nanoparticles by aqueous extract of Azadirachta indica (Neem) leaves. J. Nanopart. Res. 12(1), 237-246 (2010)

11. M. Kasithevar, M. Saravanan, P. Prakash, H. Kumar, M. Ovais, H. Barabadi, Z.K. Shinwari, Green synthesis of silver nanoparticles using Alysicarpus monilifer leaf extract and its antibacterial activity against MRSA and CoNS isolates in HIV patients. J. Interdiscip. Nanomed. 2(2), 131-141 (2017)

12. L. Rastogi, J. Arunachalam, Sunlight based irradiation strategy for rapid green synthesis of highly stable silver nanoparticles using aqueous garlic (Allium sativum) extract and their antibacterial potential. Mater. Chem. Phys. 129(1-2), 558-563 (2011) 
13. N.A. Begum, S. Mondal, S. Basu, R.A. Laskar, D. Mandal, Biogenic synthesis of Au and Ag nanoparticles using aqueous solutions of Black Tea leaf extracts. Colloids Surf. B 71(1), 113-118 (2009)

14. S. Vivekanandhan, M. Misra, A.K. Mohanty, Biological synthesis of silver nanoparticles using Glycine max (soybean) leaf extract: an investigation on different soybean varieties. J. Nanosci. Nanotechnol. 9(12), 6828-6833 (2009)

15. K. Venugopal, H.A. Rather, K. Rajagopal, M.P. Shanthi, K. Sheriff, M. Illiyas, M. Maaza, Synthesis of silver nanoparticles (Ag NPs) for anticancer activities (MCF 7 breast and A549 lung cell lines) of the crude extract of Syzygium aromaticum. J. Photochem. Photobiol. 167, 282-289 (2017)

16. L. David, B. Moldovan, A. Vulcu, L. Olenic, M. Perde-Schrepler, E. FischerFodor, A. Florea, M. Crisan, I. Chiorean, S. Clichici, G.A. Filip, synthesis, characterization and anti-inflammatory activity of silver nanoparticles using European black elderberry fruits extract. Colloids Surf. B Biointerfaces 122, 767-777 (2014)

17. P. Jigna, C. Sumitra, Phytochemical screening of some plants from western region of India. Plant Arch. 8(2), 657-662 (2008)

18. M. Govindappa, R. Channabasava, K.S. Kumar, K.C. Pushpalatha, Antioxidant Activity and Phytochemical Screening of Crude Endophytes Extracts of Tabebuia argentea Bur. \& K. Sch. Am. J. Plant Sci. 4(8), 1641 (2013)

19. S. Bhakya, S. Muthukrishnan, M. Sukumaran, M. Muthukumar, Biogenic synthesis of silver nanoparticles and their antioxidant and antibacterial activity. Appl. Nanosci. 6(5), 755-766 (2016)

20. M.P. Kahkonen, A.I. Hopia, H.J. Vuorela, K. Pihlaja, T.S. Kujala, M. Heinonen, Antioxidant activity of plant extracts containing phenolic compounds. J. Agric. Food Chem. 47, 3954-3962 (1999)

21. Y. Cai, Q. Luo, M. Sun, H. Corke, Antioxidant activity and phenolic compounds of 112 traditional Chinese medicinal plants associated with anticancer. Life Sci. 74(17), 2157-2184 (2004)

22. L. Mohanasundari, S. Suja, Qualitative phytochemical screening of rhizomes on Alpinia Calcarata and Alpinia Speciosa. J. Pharmacogn. Phytochem. 4(2), 53-56 (2015)

23. S. Pugazhendhi, E. Kirubha, P.K. Palanisamy, R. Gopalakrishnan, Synthesis and characterization of silver nanoparticles from Alpinia calcarata by Green approach and its applications in bactericidal and nonlinear optics. Appl. Surf. Sci. 357, 1801-1808 (2015)

24. A.N. Panche, A.D. Diwan, S.R. Chandra, Flavonoids: an overview. J Nutr. Food Sci. 5, e47 (2016)

25. V. Ravichandran, S. Vasanthi, S. Shalini, S.A.A. Shah, R. Harish, Green synthesis of silver nanoparticles using Atrocarpus altilis leaf extract and the study of their antimicrobial and antioxidant activity. Mater. Lett. 180 264-267 (2016)

26. T.N.J.I. Edison, Y.R. Lee, M.G. Sethuraman, Green synthesis of silver nanoparticles using Terminalia cuneata and its catalytic action in reduction of direct yellow-12 dye. Spectrochim. Acta A 161, 122-129 (2016)

27. A. Ahmad, S. Senapati, M.I. Khan, R. Kumar, R. Ramani, V. Srinivas, M. Sastry, Intracellular synthesis of gold nanoparticles by a novel alkalotolerant actinomycete, Rhodococcus species. Nanotechnology 14(7), 824 (2003)

28. S. Muthukrishnan, S. Bhakya, T.S. Kumar, M.V. Rao, Biosynthesis, characterization and antibacterial effect of plant-mediated silver nanoparticles using Ceropegia thwaitesii-an endemic species. Ind. Crops Prod. 63, 119-124 (2015)

29. N. Kanipandian, R. Thirumurugan, A feasible approach to phyto-mediated synthesis of silver nanoparticles using industrial crop Gossypium hirsutum (cotton) extract as stabilizing agent and assessment of its in vitro biomedical potential. Ind. Crops Prod. 55, 1-10 (2014)

30. A. Kalaiselvi, S.M. Roopan, G. Madhumitha, C. Ramalingam, G. Elango, Synthesis and characterization of palladium nanoparticles using Catharanthus roseus leaf extract and its application in the photo-catalytic degradation. Spectrochim. Acta A 135, 116-119 (2015)

31. P. Balashanmugam, M.D. Balakumaran, R. Murugan, K. Dhanapal, P.T. Kalaichelvan, Phytogenic synthesis of silver nanoparticles, optimization and evaluation of in vitro antifungal activity against human and plant pathogens. Microbiol. Res. 192, 52-64 (2016)

32. T.C. Prathna, N. Chandrasekaran, A.M. Raichur, A. Mukherjee, Biomimetic synthesis of silver nanoparticles by Citrus limon (lemon) aqueous extract and theoretical prediction of particle size. Colloids Surf. B 82, 152e159 (2011)
33. J.J. Mock, M. Barbic, D.R. Smith, D.A. Shultz, S. Shultz, Shape effects in plasmon resonance of individual colloidal silver nanoparticles. J. Chem. Phys. 116, 6755-6759 (2002)

34. V. Ramalingam, R. Rajaram, C. Premkumar, P. Santhanam, P. Dhinesh, S. Vinothkumar, K. Kaleshkumar, Biosynthesis of silver nanoparticles from deep sea bacterium Pseudomonas aeruginosa JQ989348 for antimicrobial, antibiofilm, and cytotoxic activity. J. Basic Microbiol. 54(9), 928-936 (2014)

35. M. Khan, M. Khan, S.F. Adil, Green synthesis of silver nanoparticles mediated by Pulicaria glutinosa extract. Int. J. Nanomed. 8, 1507-1516 (2013)

36. F. Zia, N. Ghafoor, M. Iqbal, S. Mehboob, Green synthesis and characterization of silver nanoparticles using Cydonia oblong seed extract. Appl. Nanosci. 6, 1023-1029 (2016)

37. H. Duan, D. Wang, Y. Li, Green chemistry for nanoparticle synthesis. Chem. Soc. Rev. 44(16), 5778-5792 (2015)

38. J.S. Kim, E. Kuk, K.N. Yu, J.H. Kim, S.J. Park, H.J. Lee, S.H. Kim, Y.K. Park, Y.H. Park, C.Y. Hwang, Y.K. Kim, Antimicrobial effects of silver nanoparticles. Nanomedicine 3(1), 95-101 (2007)

39. S.K. Sivaraman, I. Elango, S. Kumar, V. Santhanam, A green protocol for room temperature synthesis of silver nanoparticles in seconds. Curr. Sci. 97(7), 1055-1059 (2009)

40. G.T. Kalyanasundaram, M. Doble, S.N. Gummadi, Production and downstream processing of ( $1 \rightarrow 3)$ - $\beta$-d-glucan from mutant strain of Agrobacterium sp. ATCC 31750. AMB Express. 2(1), 31 (2012)

41. S. Vasantharaj, N. Sripriya, M. Shanmugavel, E. Manikandan, A. Gnanamani, P. Senthilkumar, Surface active gold nanoparticles biosynthesis by new approach for bionanocatalytic activity. J. Photochem. Photobiol. B 179, 119-125 (2018)

42. K. Shameli, M. Bin Ahmad, S.D. Jazayeri, S. Sedaghat, P. Shabanzadeh, H. Jahangirian, M. Mahdavi, Y. Abdollahi, Synthesis and characterization of polyethylene glycol mediated silver nanoparticles by the green method. Int. J. Mol. Sci. 13(6), 6639-6650 (2012)

43. D. Philip, C. Unni, S.A. Aromal, V.K. Vidhu, Murraya koenigii leaf-assisted rapid green synthesis of silver and gold nanoparticles. Spectrochim. Acta A 78(2), 899-904 (2011)

44. H. Bar, D.K. Bhui, G.P. Sahoo, P. Sarkar, S.P. De, A. Misra, Green synthesis of silver nanoparticles using latex of Jatropha curcas. Colloids Surf. A 339(1-3), 134-139 (2009)

45. N. Ahmad, S. Sharma, M.K. Alam, V.N. Singh, S.F. Shamsi, B.R. Mehta, A. Fatma, Rapid synthesis of silver nanoparticles using dried medicinal plant of basil. Colloids Surf. B 81, 81-86 (2010)

46. H.M. Ibrahim, Green synthesis and characterization of silver nanoparticles using banana peel extract and their antimicrobial activity against representative microorganisms. J. Radiat. Res. Appl. Sci. 8(3), 265-275 (2015)

47. K. Jyoti, M. Baunthiyal, A. Singh, Characterization of silver nanoparticles synthesized using Urtica dioica Linn. leaves and their synergistic effects with antibiotics. J. Radiat. Res. Appl. Sci. 9(3), 217-227 (2016)

48. K.D. Arunachalam, L.B. Arun, S.K. Annamalai, A.M. Arunachalam, Potential anticancer properties of bioactive compounds of Gymnema sylvestre and its biofunctionalized silver nanoparticles. Int. J. Nanomed. 10, 31 (2015)

49. B. Sadeghi, F. Gholamhoseinpoor, A study on the stability and green synthesis of silver nanoparticles using Ziziphora tenuior (Zt) extract at room temperature. Spectrochim. Acta A 134, 310-315 (2015)

50. M.V. Sujitha, S. Kannan, Green synthesis of gold nanoparticles using Citrus fruits (Citrus limon, Citrus reticulata and Citrus sinensis) aqueous extract and its characterization. Spectrochim. Acta A 102, 15-23 (2013)

51. C. Jayaseelan, R. Ramkumar, A.A. Rahuman, P. Perumal, Green synthesis of gold nanoparticles using seed aqueous extract of Abel-moschus esculentus and its antifungal activity. Ind. Crops Prod. 45, 423-429 (2013)

52. A.M. Fayaz, K. Balaji, M. Girilal, R. Yadav, P.T. Kalaichelvan, R. Venketesan, Biogenic synthesis of silver nanoparticles and their synergistic effect with antibiotics: a study against Gram-positive and Gram-negative bacteria. J. Nanomed. Nanotechnol. 6, 103-109 (2010)

53. A. Barapatre, K.R. Aadil, Jha, H: Synergistic antibacterial and antibiofilm activity of silver nanoparticles biosynthesized by lignin-degrading fungus. Bioresour. Bioprocess. 3(1), 8 (2016)

54. K. Yoon, J.H. Byeon, J. Park, J. Hwang, Susceptibility constants of Escherichia coli and Bacillus subtilis to silver and copper nanoparticles. Sci. Total Environ. 373, 572-575 (2007) 
55. K. Chaloupka, Y. Malam, A.M. Seifalian, Nanosilver as a new generation of nanoproduct in biomedical applications. Trends Biotechnol. 28(11), 580-588 (2010)

56. C.N. Lok, C.M. Ho, R. Chen, Q.Y. He, W.Y. Yu, H. Sun, C.M. Che, Proteomic analysis of the mode of antibacterial action of silver nanoparticles. J. Proteome Res. 5(4), 916-924 (2006)

57. A.M. Elgorban, A.N. Al-Rahmah, S.R. Sayed, A. Hirad, A.A.F. Mostafa, A.H. Bahkali, Antimicrobial activity and green synthesis of silver nanoparticles using Trichoderma viride. Biotechnol. Biotechnol. Equip. 30(2), 299-304 (2016)

58. S.M. Shaban, I. Aiad, M.M. El-Sukkary, E.A. Soliman, M.Y. El-Awady, Preparation of capped silver nanoparticles using sunlight and cationic surfactants and their biological activity. Chin. Chem. Lett. 26(11), 1415-1420 (2015)

59. I. Sondi, B. Salopek-Sondi, Silver nanoparticles as antimicrobial agent: a case study on E. coli as a model for Gram-negative bacteria. J. Colloid Interface Sci. 275(1), 177-182 (2004)

60. Q.L. Feng, J. Wu, G.Q. Chen, F.Z. Cui, T.N. Kim, J.O. Kim, A mechanistic study of the antibacterial effect of silver ions on Escherichia coli and Staphylococcus aureus. J. Biomed. Mater. Res. B 52(4), 662-668 (2000)

61. Y. Matsumura, K. Yoshikata, S.I. Kunisaki, T. Tsuchido, Mode of bactericidal action of silver zeolite and its comparison with that of silver nitrate. Appl. Environ. Microbiol. 69(7), 4278-4281 (2003)

62. M. Azizi, S. Sedaghat, K. Tahvildari, P. Derakhshi, A. Ghaemi, Synthesis of silver nanoparticles using Peganum harmala extract as a green route. Green Chem. Lett. Rev. 10(4), 420-427 (2017)

63. G. Franci, A. Falanga, S. Galdiero, L. Palomba, M. Rai, G. Morelli, M. Galdiero, Silver nanoparticles as potential antibacterial agents. Molecules 20(5), 8856-8874 (2015)

64. M.E. Samberg, P.E. Orndorff, N.A. Monteiro-Riviere, Antibacterial efficacy of silver nanoparticles of different sizes, surface conditions and synthesis methods. Nanotoxicology 5(2), 244-253 (2011)
65. Y. Rout, S. Behera, A.K. Ojha, P.L. Nayak, Green synthesis of silver nanoparticles using Ocimum sanctum (Tulashi) and study of their antibacterial and antifungal activities. J. Microbiol. Antimicrob. 4(6), 103-109 (2012)

66. R. Stiufiuc, I. Cristian, M. Constantin, S. Gabriela, G.D. Alina, B. Cristiana, L. Nicolae, SERS-active silver colloids prepared by reduction of silver nitrate with short-chain polyethylene glycol. Nanoscale Res. Lett. 8, 1 (2013)

67. H. Szmacinski, K. Ray, J.R. Lakowicz, Metal-enhanced fluorescence of tryptophan residues in proteins: application towards label-free bioassays. Anal. Biochem. 385, 364-538 (2009)

68. E. Paszek, J. Czyz, O. Woz'nicka, D. Jakubiak, J. Wojnarowicz, W. Łojkowski, E. Ste, pien, Zinc oxide nanoparticles impair the integrity of human umbilical vein endothelial cell monolayer in vitro. J. Biomed. Nanotechnol. 8, 957-967 (2012)

69. K. Murugan, B. Senthilkumar, D. Senbagam, S. Al-Sohaibani, Biosynthesis of silver nanoparticles using Acacia leucophloea extract and their antibacterial activity. Int. J. Nanomed. 9, 2431 (2014)

70. P. Logeswari, S. Silambarasan, J. Abraham, Eco-friendly synthesis of silver nanoparticles from commercially available plant powders and their antibacterial properties. Sci. Iran. 20, 1049-1054 (2013)

71. Y.K. Mohanta, S.K. Panda, R. Jayabalan, N. Sharma, A.K. Bastia, T.K. Mohanta, Antimicrobial, antioxidant and cytotoxic activity of silver nanoparticles synthesized by leaf extract of Erythrina suberosa (Roxb.). Front Mol. Biosci. 4, 14 (2017)

72. J.R. Soares, T.C.P. Dinis, A.P. Cunha, L.M. Almeida, Antioxidant activities of some extracts of Thymus zygi. Free Rad. Res. 26, 469-478 (1997)

73. V. Ragini, K.V.S.R.G. Prasad, K. Bharathi, Antidiabetic and antioxidant activity of Shorea tumbuggaia Rox. Int. J. Innovat. Pharma Res. 2, 113-121 (2011)

74. R.A. Larson, The antioxidant of higher plants. Phytochemistry 27, 969-978 (1988)

75. R. Subramanian, P. Subbramaniyan, V. Raj, Antioxidant activity of the stem bark of Shorea roxburghii and its silver reducing power. SpringerPlus. 2(1), 28 (2013)

\section{Submit your manuscript to a SpringerOpen ${ }^{\circ}$ journal and benefit from:}

- Convenient online submission

- Rigorous peer review

- Open access: articles freely available online

- High visibility within the field

- Retaining the copyright to your article

Submit your next manuscript at $\boldsymbol{\nabla}$ springeropen.com 